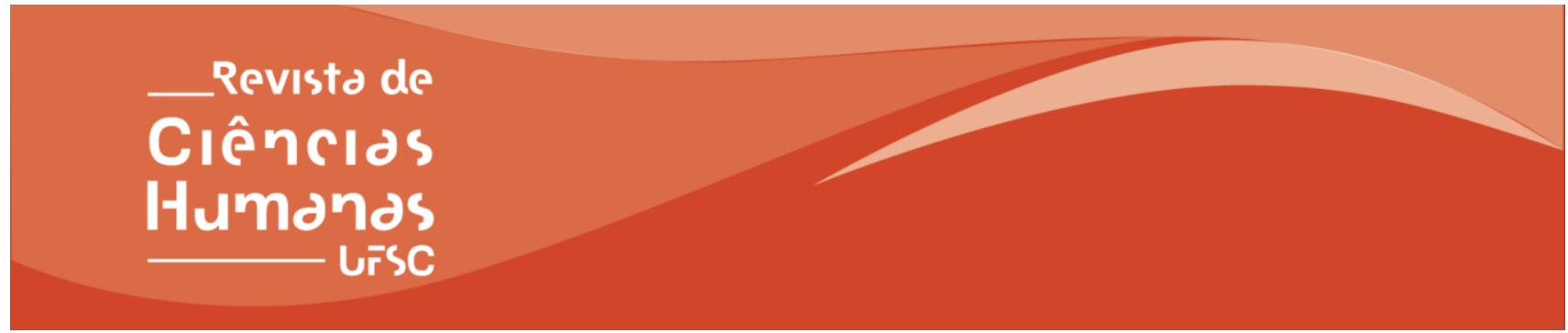

\title{
Protocolos de avaliação de risco: ferramentas para avaliar e combater a violência contra as mulheres
}

\author{
Risk of gender violence evaluation protocols: tools for evaluate and fight \\ against violence over women
}

\section{Protocolos de evaluación de riesgo: herramientas para evaluar y combater la violencia contra las mujeres}

\author{
Marlene Neves Strey $^{\mathrm{a}} \mathbb{D}$; Renata Teixeira Jardim ${ }^{\mathrm{b}}$ \\ ${ }^{\text {a }}$ Professora Doutora aposentada da Pontifícia Universidade Católica do Rio Grande do Sul - PUCRS, no programa de pós-graduação \\ em psicologia, Porto Alegre, RS, Brasil - E-mail: nevesstrey@gmail.com \\ ${ }^{\text {b }}$ Graduação em Direito pela Universidade do Vale do Rio dos Sinos (2004). Coordenadora de Programas da Themis - Gênero, Justiça \\ e Direitos Humanos. Mestre em Antropologia Social pela Universidade Federal do Rio Grande do Sul, Porto Alegre, RS, Brasil - E- \\ mail: renatateixeirajardim@gmail.com
}

\begin{abstract}
Resumo: A violência de gênero, principalmente a cometida contra as mulheres é um fenômeno mundial e está historicamente ancorada em práticas sexistas amplamente disseminadas, sendo considerada como todo ato de violência baseada no gênero que tenha ou possa ter como resultado um dano e sofrimento para as mulheres. Neste texto é apresentado o modelo integral de fases de liberação e recuperação dessas mulheres de Neus Roca Cortés e colaboradoras. Trata-se de um modelo com perspectiva de gênero buscando a compreensão da dinâmica psicossocial da mulher durante o tempo que transcorre entre a vinculação com o companheiro que exercerá a violência, até a liberação dessa violência e a reconstrução da própria vida em liberdade. São tecidas considerações sobre a necessidade de criação de instrumentos para detectar a gravidade dos riscos que as mulheres podem sofrer, como prevenção e proteção das mesmas em seu processo de busca de ajuda.
\end{abstract}

Palavras-chave: Violência de gênero. Avaliação de risco. Protocolo de avaliação.

\begin{abstract}
Gender violence, mostly when it is against women, is a global phenomenon and is traditionaly based in sexist practices widely disseminated being considered as all violent act based on gender that produce damage and suffering on women. In this text it is presented the integral model of phases on liberation and recovering of this women elaborated by Neus Roca Cortes and collaborators. It is a model with gender perspective searching comprehension of psychosocial dynamics through time between vinculation and liberation from a harmful mate and the reconstruction of her life in freedom. Considerations are made about the necessity of the elaboration of instruments to evaluate possibilities of risks suffered under violent relationships and their seriousness as a way of protection and prevention when women ask for help..
\end{abstract}

Keywords: Gender violence. Risk evaluation. Evaluation Protocol.

Resumen: La violencia de género, principalmente la cometida contra las mujeres, es un fenómeno mundial y está históricamente anclada en prácticas sexistas ampliamente diseminadas, siendo considerada como todo acto de violencia

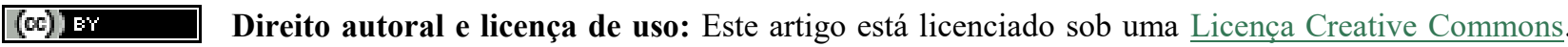
Com essa licença você pode compartilhar, adaptar, para qualquer fim, desde que atribua a autoria da obra, forneça um link para a licença, e indicar se foram feitas alterações. 
basada en el género que tenga o pueda tener como resultado un daño y sufrimiento para las mujeres. En este texto se presenta el modelo integral de fases de liberación y recuperación de esas mujeres de Neus Roca Cortés y colaboradoras. Se trata de un modelo con perspectiva de género buscando la comprensión de la dinámica psicosocial de la mujer durante el tiempo que transcurre entre la vinculación con el compañero que ejercer la violencia hasta la liberación de esa violencia y la reconstrucción de la propia vida en libertad. Hay consideraciones sobre la necesidad de crear instrumentos para detectar la gravedad de los riesgos que las mujeres pueden sufrir, como prevención y protección de las mismas en su proceso de búsqueda de ayuda.

Palabras clave: Violencia de género. Evaluación de riesgos. Protocolo de evaluación

\section{Como citar o artigo:}

STREY, M. N.; JARDIM, R. T. Protocolos de avaliação de risco: ferramentas para avaliar e combater a violência contra as mulheres. Revista de Ciências Humanas, Florianópolis, v.52. 2018. DOI: 10.5007/2178-4582.2018.56966

\section{INTRODUÇÃO}

A violência contra as mulheres é definida na Declaração sobre a eliminação da violência contra as mulheres da Assembleia Geral das Nações Unidas, de 20 de setembro de 1993, no artigo 1, como: Para efeitos da presente Declaração, por violência contra as mulheres se entende todo ato de violência baseada no gênero que tenha ou possa ter como resultado um dano e sofrimento físico, sexual ou psicológico para as mulheres, incluindo as ameaças de tais atos, a coação ou privação arbitrária de liberdade, tanto na vida pública como na privada"(ONU, 1993, P. 2). Segundo Roca Cortés et al (2015), esta definição é uma referência de autoridade amplamente utilizada em leis, relatórios e investigações na maioria dos países e âmbitos da pesquisa e da intervenção.

Cuadrado e Merino (2013), em seu Guia de Recomendações para a Detecção de Violência Machista em Homens, enfatizam que a violência machista, como qualquer relação violenta, é uma relação de domínio, controle e abuso de uma pessoa sobre outra, e a que domina se sente legitimada para obrigar a outra a fazer algo que não faria por própria vontade e para agredi-la quando ache oportuno. Diferentemente de um episódio isolado, o maltrato implica sempre um padrão psicologicamente abusivo contra a pessoa agredida. No caso da violência machista, se trata de uma violência seletiva contra as mulheres.

Bonino (2005) constata que já existe um consenso internacional para definir a violência masculina contra as mulheres como toda forma de coação, controle ou imposição ilegítima pela qual se tenta manter a hierarquia imposta pela cultura sexista, forçando-as a fazer o que não querem, que não façam o que querem, ou que se convençam de que o que o homem decide é o que deve ser feito. A violência exercida pelos homens tem causas complexas e multidimensionais, mas suas causas primárias, segundo Cuadrado e Merino (2013), são pautas culturais sexistas que mantêm e favorecem a superioridade masculina e a subordinação feminina. E, certamente, nem a biologia, nem as 
"provocações" ou a "agressividade" da mulher são fatores causais. Os valores, crenças e mandatos sobre o "que um homem deve ser", transmitidos pela sociedade tradicional e patriarcal, estão na base dessa violência. Nesse contexto, o sexismo legitima a desigualdade de poder, que situa em uma posição social dominante o homem em relação à mulher. E também com respeito a outros homens que não se comportam como tais. Esse é o germe de que se alimenta a violência machista.

Essa violência direta e explícita contra as mulheres surge em uma sociedade patriarcal constituída por desigualdades em função do gênero, preconceitos e discriminações sexistas que colocam as mulheres em uma posição desvalorizada e de subordinação com respeito aos homens, situados em uma posição de dominação, privilégio e valorização (ROCA CORTÉS et al, 2015). Como veremos com mais detalhes abaixo, a violência estrutural atua sobre as condições materiais das mulheres, disfarçadas em costumes sociais ou regulações legais. As violências simbólicas são exercidas principalmente por meio da socialização diferencial e assimétrica das mulheres, que naturaliza as assimetrias e castiga suas transgressões. E as violências diretas são as que se dão nas relações interpessoais.

As teorias feministas analisam o caráter estrutural e sistêmico dessas violências quando apontam que o sistema social patriarcal necessita do uso da força para manter-se e reproduzir-se, exercendo-a de maneira invisível e sutil, frequentemente naturalizando-a e diretamente ocultando-a (MILLET, 1969; BROWNSMILLER, 1981). Roca Cortés (2011) considera que a violência machista de casal (ou violência de gênero nas relações de casal) é um exemplo disso, pois é uma violência perpetrada no interior de relações afetivas íntimas, supostamente baseadas no amor, que seria construtivo, quando, na realidade, são relações destrutivas, criando assim um paradoxo de consequências muito especiais.

Nessa trama, o sexismo está altamente implicado, pois é o conjunto de significações que nos dão as referências simbólicas por meio das quais se possa dar sentido ao mundo das relações entre as mulheres e os homens e seus comportamentos e discursos, definindo o que é normal e o que não é normal nas relações com o fato de ser um sujeito masculino, um sujeito feminino e um sujeito heterossexual. É uma ideologia cuja função consiste em naturalizar a relação entre sexo e gênero, e fazer parecer esse último como a mera manifestação externa de uma essência contida no sexo como fato biológico, e que cada pessoa levaria em seu interior desde o momento de nascer.

Dessa maneira, a violência machista é um problema de homens que as mulheres sofrem, como a violência que sofrem pelo fato de serem mulheres e como a violência que exercem os homens para poder serem homens. A identidade masculina é uma construção psicossocial dentro de um contexto histórico e social concreto que se conforma por meio da socialização de gênero diferenciada. Uma definição clássica é a proposta por Connell (1995 apud CUADRADO; MERINO, 2013, p. 32), que 
afirma que a masculinidade "é, ao mesmo tempo, a posição nas relações de gênero, as práticas por meio das quais homens e mulheres se comprometem com essa posição de gênero, e os efeitos dessas práticas nas experiências corporais, na personalidade e na cultura". Esse processo social de construção da masculinidade tem um caráter relacional, ou seja, o masculino se define socialmente frente ao feminino. Portanto, não se define em si mesma, mas em função da alteridade. Concretamente, no caso da masculinidade, adquire a primazia do código negativo sobre o positivo (BADINTER, 1993; CONELL, 1995). Isso quer dizer que os homens aprendem antes o que não têm que fazer para construir sua masculinidade do que o que realmente têm que fazer. Isso comporta que, constantemente, tenham que demonstrar a si mesmos e aos demais que não são uma criança, que não são homossexuais e que não são uma mulher.

A visibilização e denúncia social dessa violência, surgida a partir do movimento feminista e continuada por muitas outras mulheres e homens feministas de um amplo leque social, permitiram deslegitimizar e romper a impunidade de que gozava historicamente, sendo atualmente um problema ao que as sociedades e estados devem dar resposta (MIGUEL, 2003; ROCA CORTÉS, 2013).

Para aprofundar um pouco mais essa questão, mencionamos o que Cantera (2005) entende por violência, abuso e coerção: "todo comportamento hostil, consciente e intencional que, por ação ou omissão, causa na pessoa maltratada, dano físico, psíquico, jurídico, econômico, social, moral ou sexual, atentando assim contra sua liberdade e seu direito de desenvolver-se como pessoa. Já com relação à violência de casal entre duas pessoas adultas, Roca Cortés (2011) apresenta três pontoschave: a intenção, a persistência e a vulnerabilidade. Para a autora, esses três pontos permitem diferenciar a violência da agressão. Essa diferença radica em que a agressão é uma reação defensiva contra um ataque recebido ou contra o medo de recebê-lo. Já a violência é agressão sutil ou evidente, débil ou forte, mas continuada e com a intenção de dominar a agredida ou agredido e, portanto, busca conseguir e manter seu submetimento. Também é necessário diferenciar a violência da agressividade. Segundo a Federação Espanhola de Municípios e Províncias (2012), que estabelece a violência contra as mulheres como sendo diferente de qualquer outro tipo de violência, a agressividade seria um produto da evolução biológica. A violência, no entanto, é o resultado da evolução cultural, ou mais rigorosamente, "da interação entre fatores culturais e a agressividade (SANMARTIN, 2000, p. 12). Ou seja, a violência não é apenas uma conduta atribuível à genética, mas é aprendida culturalmente.

Por outro lado, nas relações interpessoais afetivas, como em outras violências, as vulnerabilidades do outro são aproveitadas ou são provocadas para ganhar posições de domínio, ainda que seja com a agressão, embora seja uma relação de "amor". Segundo Roca Cortés et al (2015), a lista de vulnerabilidades do ser humano, sejam homens ou mulheres, é interminável. E nas relações de casal, como relações de intimidade, é onde essas vulnerabilidades se mostram de maneira mais 
aberta e confiada, é o lugar em que se conhecem todos os pontos de apoio nos quais se assentam a sobrevivência e a dignidade das pessoas.

\section{CLASSIFICAÇÕES DAS VIOLÊNCIAS}

Existem inúmeras possibilidades de classificação das violências. Para este texto escolhemos a orientação da Proposta de Intervenção Integral no Âmbito Local Contra a Violência Sobre a Mulher (Federação Espanhola de Municípios e Províncias, 2012). As contribuições de Galtung (1998); a violência simbólica de Bordieu (1994); as contribuições de Días-Aguado (1996) e a Organização Mundial da Saúde (2002).

Galtung (1998) distingue três tipos de violência interrelacionados: a violência direta (visível na forma de condutas contra pessoas, grupos ou organizações, incluída a do próprio Estado); a violência estrutural (referida a situações de exploração, discriminação ou marginalização que poderiam ser evitadas com outros modelos de sistema social ou econômico, por exemplo); violência cultural (contra povos, coletivos, grupos sociais, que se baseia na legitimação teórica que proporcionam argumentos racionais, crenças, ideias, que, por sua vez, estão provocando violência direta ou estrutural).

Bourdieu (1994), por sua vez, contribui com a expressão violência simbólica, que complementa os tipos acima, em especial as violências estruturais e culturais, pois permite comprovar que existem significados sociais impostos, nem sempre de modo consciente, que se somam às crenças pessoais e se fortalecem. Por sua vez, Días-Aguado (1996) distingue entre violência expressiva e violência instrumental. A primeira é produzida quando a pessoa ou o grupo fica incapaz de superar uma situação e, como consequência dessa incapacidade, pode "explodir" com agressividade. A segunda é a utilizada para conseguir um determinado fim. Nesse caso, quem utiliza a violência tem sempre um objetivo instrumental: conseguir a anulação total ou parcial de outra pessoa por meio da força para quebrar a integridade física ou psicológica da vítima (MONTERO GOMES, 2007). A violência de gênero tem um caráter basicamente instrumental.

A Organização Mundial da Saúde (OMS) (2002) define violência como: "o uso intencional da força ou o poder físico, de fato ou como ameaça, contra si mesmo, outra pessoa ou um grupo ou comunidade, que cause ou tenha muitas probabilidades de causar lesões, morte, danos psicológicos, transtornos do desenvolvimento ou privações”. Essa definição vincula intenção e ato violento, de modo independente às consequências que são produzidas e, por outra parte, exclui os atos violentos não intencionais, como por exemplo os acidentes de trânsito. Nessa definição são três os tipos de violência: violência auto-infligida, violência interpessoal e violência coletiva. A OMS também 
diferencia a violência física, sexual, psicológica e a baseada em privações e negligência. O Conselho de Europa acrescenta a essas formas, a violência econômica (negar acesso ao dinheiro, impedir o acesso a um posto de trabalho ou à educação etc.); a violência espiritual (condutas que consistem em obrigar uma pessoa a aceitar um sistema de crenças cultural ou religioso determinado ou dirigidas a abalar as crenças da pessoa por meio do ridículo ou do castigo).

Tendo em conta o marco descrito acima, a violência contra as mulheres apresenta os três tipos propostos por Galtung (1998) - direta, estrutural e cultural -; tem um forte poder simbólico, porque reafirma a ideia da subordinação feminina; é instrumental, porque os agressores a utilizam como um meio para conseguir um resultado, a dominação; e todos os tipos de violência mencionados pela OMS afetam de forma especial as mulheres, porque, como a Anistia Internacional (2008) denuncia, "as mulheres e meninas sofrem de maneira desproporcionada a violência: na paz e na Guerra, em mãos do Estado, da comunidade e da família". As mulheres, pelo simples fato de serem mulheres, correm o risco de sofrer violência física, psicológica, sexual, econômica e espiritual, em sua vida privada e em sua vida pública.

A violência de gênero é reflexo da tradição cultural das sociedades patriarcais e forma parte da construção social da realidade nessas sociedades, pois responde a uma parte substantiva do sistema de interpretação de sua experiência: o machismo. Também se fundamenta em um dos componentes do substrato emocional que configura o intercâmbio dinâmico entre seus membros, a desigualdade. E, além disso, se reproduz segundo uma das pautas dominantes que conformam seu comportamento, o emprego da força. O lugar de mulheres e homens no mundo é aprendido ou é performático como quer Butler (2001). Quando os requerimentos sociais e culturais não são "obedecidos”, aumenta o risco de castigo. É nesse contexto que, em geral, se produz a violência contra as mulheres. Tal dominação é parte do discurso de uma sociedade patriarcal e, por isso, como assinala Teubal (2001), a violência contra as mulheres é um problema social e político relacionado com a distribuição de poder entre homens e mulheres.

Conforme se pode constatar na breve revisão acima, existem inúmeros e diferenciados conceitos que tratam sobre a violência exercida contra as mulheres (violência machista, violência masculina contra as mulheres, violência machista de casal, violência de gênero). Cada conceito tem suas especificidades, mas, pode-se encontrar uma relação entre todos e cada um desses diferentes conceitos: embora homens e mulheres sofram violências ao longo de suas vidas, em seus contextos culturais e sociais, são as mulheres o principal objeto contra o qual se exerce a violência. Essas violências variam desde as relações íntimas de casal e na família, até as sociais e culturais devido principalmente às relações de poder desiguais entre os gêneros. Neste texto, queremos enfatizar a violência exercida contra as mulheres, independentemente das sutilezas específicas dos diferentes 
conceitos que tratam, de alguma forma, do tema das mulheres que vivem em situação de violência. Além disso, apresentamos um modelo que busca mostrar como se dá o processo, suas fases de desenvolvimento e a possibilidade de superação e afastamento da situação de violência. Para dar conta da violência descrita no modelo, apresentamos um protocolo de avaliação de risco que é uma ferramenta importante para quem trabalha com mulheres em situação de violência.

\section{MODELO INTEGRAL DE FASES DE LIBERAÇÃO E RECUPERAÇÃO DE MULHERES EM SITUAÇÃO DE VIOLÊNCIA MACHISTA DE CASAL}

No contexto espanhol, um dos nomes de referência na pesquisa e intervenção com mulheres em situação de violência é Neus Roca Cortés, pesquisadora do Departamento de Psicologia Social da Universidade de Barcelona. Roca Cortés et al. (2015) na obra Recuperação das Mulheres em Situação de Violência Machista de Casal, apresenta um modelo integral de fases de liberação e recuperação dessas mulheres. As pesquisadoras realizaram a pesquisa e a elaboração do modelo a partir da Universidade de Barcelona (Neus Roca Cortés e Juana Espín) e dos serviços sociais básicos do Distrito Nou Barris de Barcelona (Montserrat Paino Lafuente, Laura Córdoba del Águila e Matilde Albarracín Soto). Trata-se de um modelo com perspectiva de gênero buscando a compreensão da dinâmica psicossocial da mulher durante o tempo que transcorre entre a vinculação com o companheiro que exercerá a violência, até a liberação dessa violência e a reconstrução da própria vida em liberdade. Os objetivos da pesquisa foram descrever o processo de recuperação das mulheres nas diferentes fases; outorgar fiabilidade e validar instrumentos de medida da recuperação que incorporem as dimensões psicológicas, de saúde e de inserção social; utilizar esses instrumentos para o diagnóstico das mulheres, para a avaliação da intervenção e para a investigação sobre fatores e processos básicos de recuperação.

A descrição se centra nas reações e posicionamentos das mulheres pesquisadas para a elaboração do modelo com respeito ao paradoxo que essa violência implica e que se concretiza em uma mescla de contrários: afeto e dor, confiança e agressão continua, crescimento pessoal e alienação, desejo amoroso, amparo afetivo e, por sua vez, uma relação de dominação. Essa é considerada uma relação paradoxal de casal e/ou de família, porque contém a construção de um projeto vital comum e, ao mesmo tempo, a sua destruição.

As fases do Modelo foram descritas a partir de uma perspectiva holística e dinâmica e desde o significado subjetivo das mulheres estudadas. O centro do Modelo é a mulher que interpreta ativamente a situação, a avalia e reage vitalmente a ela em primeiro lugar, no sentido de voltar a ter uma relação que havia sido satisfatória e, mais adiante, para desprender-se da relação destrutiva. 
Nesse sentido, o Modelo encara essa mulher mais do que uma vítima, uma sobrevivente, porém, isso não implica que se desestime o que é prejudicial: o mal-estar físico, o esgotamento psicológico, o medo permanente, a vulnerabilidade psicossocial que a violência busca e consegue, e a posição relacional de submissão e coerção na qual se encontra a agredida.

O Modelo também não parte do comportamento do violento, mas das vivências da mulher e, portanto, explica suas reações e não descreve a violência que recebe. A violência do companheiro maltratador está presente em todas as fases e adquire formas diferentes de acordo com as normas sociais, a mentalidade e personalidade de quem a exerce e as próprias circunstâncias da relação (HIRIGOYEN, 2006; JOHNSON, 2006; LORENTE, 2006 apud ROCA CORTÉS et al., 2015). As formas que adota o exercício da violência de casal se adaptam às circunstâncias, características e reações do outro membro do casal. Na violência de casal, as mulheres encontram que, em lugar de obter amor, e de onde o haviam recebido, agora recebem feridas, dor e submetimento, com restos de afeto e descaso. Esse paradoxo gera confusão e alienação.

O processo de liberação é, para as sobreviventes, uma luta interna entre duas forças contrárias e contraditórias. Por uma parte, a escolha dessa pessoa para uma relação de convivência íntima, de encontrar companhia para o próprio projeto de vida, uma relação da qual esperam um trato de respeito e igualdade, ou da qual se espera que cada um contribua com sua parte do contrato; um projeto vital que frequentemente inclui formar uma família. E por outra parte, a força contraria: o amor inicial que se converte em sofrimento, competição, esforço continuo e esgotante quando se pretende manter a ilusão de vida da qual havia surgido; também se encontra a alienação, medo, humilhação, submetimento, inclusive escravidão pelas palavras de algumas pesquisadas. Primeiro se encontra a insatisfação e depois a destruição.

Cada fase do Modelo se explica a partir de elementos detectados como substanciais e diferenciais desse período. Elas são sequenciais, transcorrem uma após a outra, há que passar por uma para chegar à seguinte, porém os elementos constitutivos de cada fase são paralelos e estão interconectados, sucedem ao mesmo tempo. Apesar da sequencialidade das fases, a direção não é única, se adianta mas também se produzem retrocessos. As pesquisadoras observaram mulheres estancadas em uma fase ou que deram marcha atrás, somando assim mais anos à situação de violência.

O Modelo conceitua critérios que distinguem umas fases das outras e elementos de outros similares explicados em outras fases. Esses critérios distintivos permitem detectar, quando se tenta compreender um caso particular a partir da sequência-tipo, quais são os elementos que estão descolocados, ensaiar explicações ou predições e decidir conteúdos e tipos de intervenções, assim como estratégias de intervenção. 
O Modelo apresenta sete Fases: Vinculação (desejo de relação de casal, reconhecimento de comportamentos indesejáveis, centrada na relação). Resistência (responsabilidade e culpabilidade pela violência; minimização, justificação e ocultação da violência; esforços pela relação e esperança de mudança; diminuição do impacto do abuso; refúgio em espaços próprios positivos; insatisfação, confusão e mal-estar psicofísico). Conflito e ambivalência (conflito expresso como queixa e necessidade de mudança: busca de alternativas internas e ajudas externas para frear a violência). Questionamento (associação do mal-estar geral físico à agressão continuada; identificação interna como violência e seu questionamento; identificação externa da violência com escuta; empoderamento com ensaios de separação; reavaliação da relação; a possibilidade de separar-se). Confrontação e ruptura (enfrentando-se empoderada ao abuso e ao abusador; reavaliação da relação: rechaço e enfrentamento; busca de ajuda externa para separar-se; prepara ativamente sua sobrevivência autônoma e os assuntos legais). Manter-se livre (luta pela sobrevivência, pela segurança e por manter-se livre; reavaliação da relação: reafirmação das mudanças; cuida de suas relações sociais e de sua saúde). Reconstrução do futuro em liberdade (busca de novos significados da relação vivida e novo sentido do eu; tem cuidado da saúde e da relação com os filhos e filhas e com o resto da família; novos projetos de vida e de futuro; novas crenças sobre violência, relações de casal e familiares).

As autoras detalham cada aspecto das fases do Modelo Integral e discutem suas possibilidades. Além disso, apresentam uma série de instrumentos para serem utilizados em cada uma das fases e para acompanhamento posterior.

\section{A AVALIAÇÃO DE RISCO DE VIOLÊNCIA DE GÊNERO SOBRE AS MULHERES}

Tomando como base o modelo acima de violência contra as mulheres, é importante lembrar que em cada uma de suas fases as mulheres podem estar e estão correndo diferentes tipos de risco. Elas podem ou não estar conscientes desses riscos. Seja como for, minimizar esses riscos, ou mesmo negá-los, pode ser uma ameaça à própria vida dessas mulheres. Provavelmente, sozinhas, terão dificuldades para lidar com esses riscos e de estabelecer estratégias de enfrentamento dos mesmos. A ajuda externa costuma ser fundamental nesse sentido.

No entanto, existem múltiplas dificuldades para reconhecer a violência de gênero, tanto por parte das mulheres que a sofrem, como por parte de profissionais do sistema que atende às mesmas. Isso tem a ver com fatores sociais, tais quais os mitos e estereótipos criados pela cultura, com fatores psicológicos como o temor a enfrentar os medos e a dor emocional, e, além disso, nos profissionais, pode-se somar a falta de formação nesse material. O Protocolo Comum para a atuação sanitária diante 
da violência de gênero (2012) ainda lembra que outras vulnerabilidades, tais como as portadoras de deficiências físicas e mentais, as imigrantes, as que vivem em ambientes rurais, as idosas, as prostitutas, as drogodependentes e outras circunstâncias que as coloque em situação de exclusão social, aumentam essas dificuldades de reconhecimento.

Embora este texto tenha a intenção apresentar o modelo espanhol (ROCA CORTÉZ et al., 2015) e o Protocolo RVD-BCN abaixo descrito, é importante assinalar que o tema interessa a quem pesquisa e trabalha com a violência contra as mulheres em seus diferentes âmbitos em nosso País, já que também aqui a violência contra as mulheres pode ser considerado um problema de saúde pública devido à sua dimensão. Inúmeros estudos, aqui no Brasil, voltaram-se para a questão dos fatores de risco, variando em metodologia e enfoque teórico, com resultados às vezes contrastantes, às vezes complementares. Podemos citar alguns: Fatores de Risco para Violência Contra a Mulher no Contexto Doméstico e Coletivo (Vieira et al., 2008); Violência intrafamiliar baseada em gênero com implicação de risco de vida: mulheres abrigadas na Casa Abrigo Maria Haydée/Rio Mulher/Rio de Janeiro" (CARNEIRO; OLIVEIRA, 2008); Violência conjugal física contra a mulher na vida: prevalência e impacto imediato na saúde, trabalho e família (MIRANDA et al, 2010); O estigma da violência sofrida por mulheres na relação com seus parceiros íntimos (MOREIRAet al, 2011); A violência doméstica a partir do discurso de mulheres agredidas (ZANCAN et al, 2013). Todos esses estudos e muitos outros mostram que é fundamental ter ciência dos riscos que as mulheres correm a fim de que se possa enfrentar a situação e realizar o melhor encaminhamento possível para sua superação. $\mathrm{Na}$ Espanha já foram elaborados alguns instrumentos para avaliar os riscos que sofrem as mulheres em situação de violência, atendidas nos diferentes serviços oferecidos a elas em todo o território espanhol. São instrumentos já validados que têm oferecido ajuda importante na previsão de riscos, fornecendo a base sobe a qual podem ser articuladas estratégias de enfrentamento e soluções, temporárias ou mais definitivas, para proteção das mesmas.

Para mostrar um exemplo de protocolo de avaliação de risco de violência contra a mulher e em coerência com o embasamento teórico oriundo da Espanha escolhemos o Protocolo de avaliação de risco do Circuito de Barcelona (RVD-BCN, 2011). Primeiramente, o Circuito de Barcelona Contra a Violência Contra as Mulheres nasceu em 2001, com o impulso da Prefeitura de Barcelona e o Consórcio Sanitário daquela cidade espanhola, com a finalidade de promover a coordenação e a cooperação entre as diferentes instituições implicadas na luta para a erradicação da violência machista (nomenclatura utilizada por suas/eus criadoras/es) em Barcelona, como condição necessária para poder oferecer uma atenção de qualidade às mulheres que estão vivendo situações de violência e a seus filhos e filhas, considerando a dimensão preventiva. A ideia era dar impulso a um trabalho em rede efetivo entre os diferentes serviços e profissionais que intervêm em distintos âmbitos (serviços 
sociais, saúde, polícia, justiça, âmbito judicial e educação), com a finalidade de atuar de maneira mais eficiente diante das situações de violência contra as mulheres, atender com maior qualidade as pessoas afetadas e potenciar as estratégias preventivas. O dispositivo público da cidade de Barcelona abriga todos os serviços sociais que têm a responsabilidade de detectar situações de violência machista. Trata-se de uma ampla rede com a finalidade de atender não só mulheres, mas meninas/os e adolescentes, buscando, juntamente com os demais serviços que intervêm a articulação entre todos eles para tentar compartilhar uma visão global do que ocorre e do que está sendo feito, tentando conseguir a coerência das atuações e evitando a vitimização secundária das pessoas atendidas. Além disso, formam a rede: Os Pontos de Informação e Atenção às Mulheres (PIAD), a Equipe de Atenção às Mulheres (EAD), o Centro Municipal de Acolhida de Urgência por Violência Machista (CMAUVM), as Casas e Apartamentos de acolhida de longa estada, o Serviço de atenção a meninas e meninos que sofrem violência de gênero (SAN), o Serviço de Atenção Socioeducativa da Agência ABITS (para prostitutas), o Serviço de Atenção a Homens para a Promoção de relações não violentas (SAH) e a Equipe de Atenção à Infância e à Adolescência (EAIA).

O Circuito permitiu alcançar os requisitos necessários para um trabalho em rede eficaz e produtivo que possibilitou a construção de uma ferramenta conjunta muito melhor que cada uma das utilizadas até então pelos diferentes serviços participantes. Por essa razão o protocolo incorpora em seu nome as iniciais da cidade de Barcelona. Esse instrumento foi validado cientificamente entre o mês de fevereiro de 2010 e junho de 2011. No processo de validação participaram profissionais e serviços de todos os âmbitos implicados de justiça, saúde, serviços sociais e corpos policiais, tendo sido dirigido pelo Grupo de Estudos Avançados em Violência (GEAV) da Universidade de Barcelona e financiado em partes iguais pela Prefeitura de Barcelona, o Consórcio Sanitário de Barcelona e o Instituto Catalão de Mulheres. A Direção do Programa de Mulher da Prefeitura foi a encarregada da coordenação de todo o processo e da Comissão Técnica Interinstitucional que realizou o seguimento. Então, o RVD-BCN é uma ferramenta que ajuda aos/às profissionais que atendem a mulheres que vivem situações de violência machista e avaliar o risco de que a curto prazo sejam produzidos atos violentos graves por parte de seu companheiro ou ex-companheiro. Essas mulheres devem morar no município de Barcelona e viver ou haver vivido em situação de violência. Os serviços atendem a todas as mulheres, assim como meninos, meninas e adolescentes que cumpram esses dois requisitos, mesmo que não estejam inscritas como moradoras na Prefeitura Municipal, já que prevalece, segundo a filosofia dos serviços, a situação real acima da situação administrativa. Caso sejam estrangeiras, não importa que sua situação seja legalizada, ou não. Tampouco é necessário que tenham realizado denúncia ou que estejam vivendo (ou não) com a pessoa agressora. Nenhum impedimento de 
atendimento é dado por seu estado de saúde física e mental, deficiência, situação legal, orientação sexual ou procedência.

O protocolo coleta os dados da mulher atendida e a história da conduta violenta do companheiro ou ex-companheiro. Levanta, também, as ameaças e/ou abusos graves contra a mulher, além das circunstâncias agravantes e fatores de vulnerabilidade da mulher e a percepção da situação de risco por parte da atendida. A partir desses dados, é feita a soma das respostas afirmativas/avaliação do risco, que pode ser categorizado como baixo, médio ou alto. Após, são investigados outros fatores-chave que não constaram anteriormente e é feita a avaliação do risco e arquitetada a atuação em função do risco atual existente e as circunstâncias previsíveis que podem aumentar o nível de risco no futuro (alerta). Também compõem o protocolo os dados de quem fez a avaliação.

O formulário deve ser preenchido pelo/a profissional (pertencente aos diferentes serviços mencionados acima) que está atendendo a mulher e isso deve ser feito a partir da informação que ela própria forneça. Também se se tem acesso, a partir da informação que é proporcionada por outros serviços e da documentação disponível (sentenças judiciais etc.). As perguntas não devem ser formuladas como se tratasse de um questionário. Frequentemente a mulher proporciona informação útil de forma espontânea, ou, então, é o/a profissional quem pergunta à mulher, de forma flexível e no momento oportuno no contexto da entrevista ou, segundo o tipo de serviço de que se trate e como se encontre a mulher no curso de várias entrevistas. Finalmente, o protocolo não está desenhado como um questionário que a mulher possa preencher diretamente.

Assim como o Protocolo brevemente descrito acima, existem inúmeros outros, tanto na Espanha, quanto em outros países Europeus. No Brasil, estamos começando a nos preocupar mais profundamente com a criação de instrumentos que ajudem a avaliar os riscos que correm as mulheres que vão em busca de ajuda nas diferentes instituições existentes para lidar com a violência de gênero. São estudos extremamente necessários para que possamos contar com material de uso prático na proteção das mulheres em situação de violência.

\section{ALGUMAS PALAVRAS COMO CONCLUSÃo}

A Declaração de Antígua Contra a Violência Baseada no Gênero (2003 apud STREY, 2004, p. 16) "este tipo de violência é uma violação dos direitos humanos e um problema de saúde pública de enormes proporções e graves consequências". Acabar com a violência de gênero (entre outras violências) é de importância diretamente proporcional ao tamanho desse problema. Sabe-se que, como vimos acima, que é difícil, inclusive, até mesmo diagnosticar quando a violência acontece. No 
entanto, mesmo sendo um fenômeno tão complexo e, principalmente devido a isso, é necessário desenvolver esforços e ferramentas (para podermos fazer com que esses esforços valham a pena) para tornar as ações políticas e as dos/as profissionais que atuam na área da violência de gênero cada vez melhores e mais eficazes em seu combate.

O Modelo Integral de Fases de Liberação e Recuperação de Mulheres em Situação de Violência Machista de Casal e o Protocolo de avaliação de risco do Circuito de Barcelona foram apenas dois exemplos dos estudos que estão se desenvolvendo para compreender e prever os riscos que as mulheres que buscam ajuda nas instituições que tratam do problema sofrem, às vezes sem se dar conta, ou, se se dão conta, sem saber o que fazer para superar os riscos. E o impasse mais doloroso acontece quando quem deve ajudar na solução, na tomada de medidas ou, pelo menos nas tentativas de prevenção, quando isso ainda é possível, tampouco sabem exatamente o que fazer.

Nesse sentido, a formação de quem trabalha na área da saúde e na sua contraparte, a violência de gênero, deve ser bem sustentada pelos estudos de gênero, pelas discussões sobre a violência de gênero e pelas pesquisas que tornam possível a criação de instrumentos de detecção cada vez melhores. Escapar da violência de gênero nem sempre é fácil como mostraram Villavicencio e Sebastian (2001) ou, às vezes nem sequer é possível (ROCA CORTÉS et al. 2005). Isso não significa que deve-se desistir de enfrentá-la. Muito pelo contrário, isso deve ser estímulo para envidarmos ainda mais esforços no seu combate e, num mundo ideal, a sua erradicação. Esperamos que as duas pesquisas espanholas (Modelo Integral de Fases de Liberação e Recuperação de Mulheres em Situação de Violência Machista de Casal e Protocolo RVD_BCN de avaliação de risco de violência de casal contra a mulher) possa ser fonte de reflexão e ajuda no estudo do tema por parte de quem investiga o assunto em nosso País.

\section{REFERÊNCIAS}

AMNISTIA INTERNACIONAL. Obstinada realidad, derechos pendientes. Tres años de la ley de medidas de protección integral contra la violencia de género. España.

BANDINTER, Elizabeth. XY: La identidad masculina. Madrid: Alianza Editorial, 1993.

BONINO, Luís. La violencia masculina en la pareja. In: Cárcel de amor: relatos culturales sobre la violencia de género. Madrid: Museo de Arte Contemporaneo Reina Sofia, 2005.

BOURDIEU, Pierre. Raison pratiques. Sur la théorie de l'action. Paris: Éditions du Seuil, 1994. 
BROWNMILLER, Susan. Contra nuestra voluntad: hombre, mujeres y violación. Madrid: Planeta, 1981.

BUTLER, Judith. Corpos que pesam: sobre os limites discursivos do sexo. In: LOURO, Guacira Lopes (Org.). O corpo educado. Balo Horizonte: Autêntica Editora, 2001.

CANTERA, Leonor. Violencia en la pareja: espejo del atropello, desconstrucción del amor. In: Cantera (Org.) La violencia a casa. Barcelona: Fundació Caixa Sabadell, 2005.

CARNEIRO, Alcides; OLIVEIRA, Soraya. Violencia intrafamiliar baseada em gênero com implicação de risco de vida: mulheres abrigadas na Casa Abrigo Maria Haydée/Rio Mulher/ Rio de Janeiro. XVI Encontro Nacional de Estudos Populacionais da ABEP. Caxambú, 2008.

CONNELL, Raewyn. Masculinities. California: University of Calinfornia Press. 1995.

CUADRADO, Aharon; MERINO, Bárbara. Guia de recomendaciones para la detección de violencia machista en hombres. Barcelona: Circuito Barcelona contra la violencia hacia las mujeres/ Ajuntament de Barcelona, 2013.

DÍAZ-AGUADO, María José. Programas de educación para la tolerancia y prevención de la violencia. In: S. Yubero (Org.). EI desafío de la educació social. Universidad de Casilla- La Mancha, 1996.

FEDERACIÓN ESPAÑOLA DE MUNICIPIOS Y PROVINCIAS. Propuesta de intervención integral en el ámbito local contra la violencia sobre la mujer. Madrid: Federación Española de Municipios y provincias, 2012.

GALTUNG, Johan. Tras la violencia, $3 \mathbf{R}$ : reconstrucción, reconciliacióon, resolución. Afrontamiento de los efectos visibles e invisibles de la guerra y la violencia. Bilbao: Bakeaz/Gernika Gogoratuz, 1998.

HIRIGOYEN, Marie-France. Mujeres maltratadas. Los mecanismos de la violencia en la pareja. Barcelona: Paidós, 2006.

JOHNSON, Michel. Conflict and control: Gender symmetry and asymmetry in domestic violence. Violence Against Women, vol 12, n. 11, p. 1003-1019.

LORENTE, Miguel Acosta. El rompecabezas: anatomía del maltratados. Barcelona: Crítica, 2006. 
MIGUEL, Ana de. La violencia de género: la construcción de un marco feminista de interpretación. Cuadernos de Trabajo Social, 18, 2003.

MILLET, Kate. Teoría de la política sexual. A Política sexual. Madrid: Cátedra, 1969.

MIRANDA, Milma Pires de Melo; PAULA, Cristiane Silvestre; BORDIN, Isabel Altenfelder. Violência conjugal física contra a mulher na vida: prevalência e impacto imediato na saúde, trabalho e família. Revista Panamericana Salud Pública, v. 27, n. 4, p. 300-308, 2010.

MONTERO GÓMEZ, A. Consideraciones sobre especialización profesional en psicología sobre violencia de género. Themis Revista Jurídica de Igualdad de Género, N. 2, p. 53-55, 2007.

MOREIRA, Virgínia; BORIS, Georges Janja Bloc; VENÂNCIO, Nadja. O estigma da violência sofrida por mulheres na relação com seus parceiros íntimos. Psicologia \& Sociedade, v. 23, n. 2, p. 398-406, 2011.

ONU. Declaración sobre la eliminación de la violencia contra la mujer. Resolución de la Asamblea General de las Naciones Unidas 48/104, de 20 de diciembre, 1993.

ORGANIZACIÓN MUNDIAL DE LA SALUD (OMS). Informe mundial sobre la violencia y la salud. Washington DC, 2002.

PROTOCOLO COMÚN PARA LA ACTUACCIÓN SANITARIA ANTE LA VIOLENCIA DE GÉNERO. Informes, estudios e investigación. Madrid: Ministerio de Sanidad, Servicios Sociales e Igualdad, 2012.

ROCA CORTÉS, Neus. Intervención grupal y violencia sexista: marco conceptual. In: Roca Cortés, N.; MASIP SERRA, J. (Orgs.) Intervención grupal en violencia sexista. Experiencia, investigación y evaluación. Barcelona: Herder, 2011.

- Violencia íntima o violencia machista de pareja? Su visibilidad desde una perspectiva de género y feminista. Notas de la experiencia en España. La Camera Blu, Journal of gender studies, 10, p. 243-274, 2013.

et al. Recuperación de las mujeres en situación de violencia machista de pareja. Barcelona: Ayuntamiento de Barcelona/ Universitat de Barcelona/ Fundación Salud y Comunidad, 2015.

et al. Cambio de creencias e intervención en mujeres que sufren maltrato. Eliminar obstáculos para alcanzar la igualdad. Universitat Jaume I 1, p. 143-155, 2005. 
RVD-BCN. Protocolo de valoración del riesgo de violencia contra la mujer por parte de su pareja o expareja. Barcelona: Circuito Barcelona Contra la Violencia Hacia las Mujeres, 2011. SANMARTIN, José. La violencia y sus claves. Barcelona: Ariel, 2000.

STREY, Marlene Neves. Violência de gênero: uma questão complexa e interminável. In: STREY, M. N.; AZAMBUJA, M.P.R.; jaeger, f. P. (Orgs). Violência, Gênero e Políticas Públicas. Porto Alegre: EDIPUCRS, 2004.

TEUBAL, Ruth et al. Violencia familiar, trabajo social e instituciones. Buenos Aires: Paidós, 2001.

VIEIRA, Luiza Jane Eyre de Souza et al. Fatores de risco para violência contra a mulher no contexto doméstico e coletivo. Saúde e Sociedade, v. 17, n. 3, p. 113-125, 2008.

VILLAVICENCIO, Patricia Carrillo; SEBASTIÁN, Julia. Violencia doméstica: su impacto en la salud física y mental de las mujeres. Madrid: Instituto de la Mujer, 2001.

ZANCAN, Natália; WASSERMANN, Virgínia; LIMA, Gabriela Quadros. A violência doméstica a partir do discurso de mulheres agredidas. Pensando Famílias, v. 17, n. 1, 2013, p. 63-76.

Recebido em: 21-5-2018

Histórico Revisado em: 11-7-2018

Aceito em: 5-9-2018

Financiamento CAPES. Processo BEX 0890/15-4 - Bolsa de Pós-Doutorado Sênior. 2015-2016 